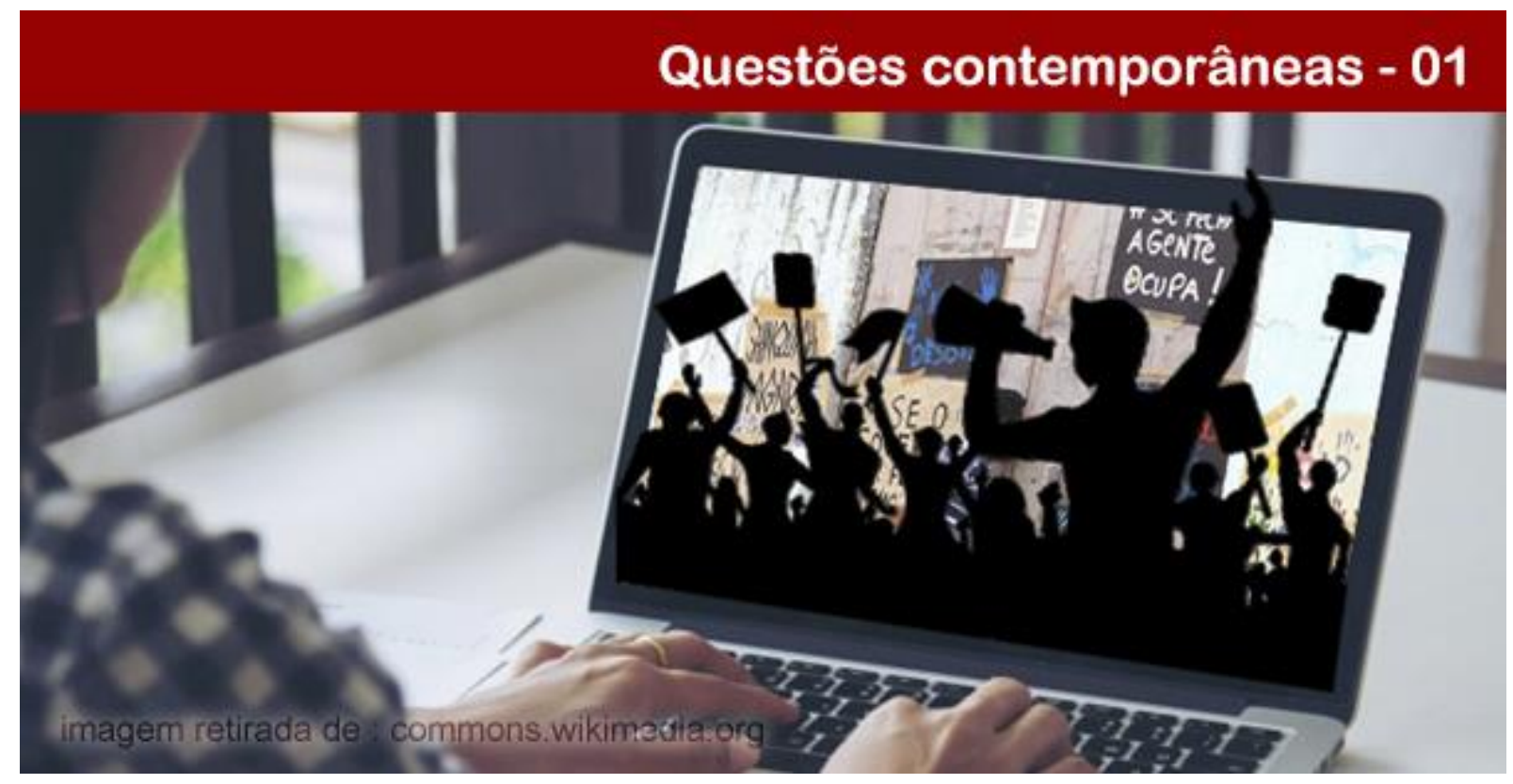

\title{
REDES SOCIAIS DIGITAIS: A LÓGICA DO PENSAMENTO SOCIAL EM EVENTOS DE MOBILIZAÇÃO COLETIVA
}

Georgie Echeverri Vásquez

Doutorando e Mestre em Psicologia Social pela Universidade do Estado do Rio de Janeiro (UERJ). Comunicador Social - Jornalista pela Universidad Pontificia Bolivariana (UPB) - Colômbia. E-mail: mensajerodevida@gmail.com.

\section{Regina Glória Nunes Andrade}

Doutora em Comunicação pela Universidade Federal do Rio de Janeiro (UFRJ). Professora Visitante do Programa de Pós-Graduação em Psicologia Social da Universidade do Estado do Rio de Janeiro (UERJ). E-mail: reginagna@terra.com.br.

Resumo: O presente texto aborda a relação entre o conteúdo de uma rede social digital e a dinâmica de formação do pensamento social nesse ambiente virtual. A partir da análise comunicacional de três eventos da história recente, nomeadamente, a rejeição ao acordo de paz com as FARC (Forças Armadas Revolucionárias da Colômbia) na Colômbia, o Brexit ou saída do Reino Unido da União Europeia e a ocupação das escolas do Rio de Janeiro por parte dos estudantes secundaristas em 2016, o artigo associa a construção de narrativas múltiplas, próprias da Internet, aos princípios de estabilidade e variabilidade que regem a arquitetura do pensamento social. Por fim, concentra-se na descrição das condições de produção desse tipo de pensamento (formalismo espontâneo, dualismo causal, primazia da conclusão e construção de analogia) no intuito de compreender a coerência de sua lógica.

Palavras-chave: Redes sociais digitais. Pensamento social. Comunicação. Mobilização.

\section{SOCIAL MEDIA AND MOBILIZATION: THE LOGICS OF THE SOCIAL THOUGHT}

Abstract: This paper deals with the relationship between content in a social media and the formation of social thought in such a virtual environment. Based on the communication analysis of three events in recent history, namely, the rejection of the peace agreement with the FARC (Revolutionary Armed Forces of Colombia) in Colombia, the Brexit or withdrawal of the United Kingdom from the European Union and the occupation of Rio de Janeiro schools by the students in 2016, the article associates the construction of Internet multiple narratives to the principles of stability and variability that shape the architecture of social thought. Finally, it focuses on the depiction of the conditions of production of that kind of thinking (spontaneous formalism, causal dualism, primacy

\section{POLÊM!CA $\mid$ LABORE (}

Polêmica - Revista Eletrônica da Uerj - Rua São Francisco Xavier, 524, $1^{\circ}$ andar bloco D, sl.1001 • Tels.: +55 21 2334-4088 / 4087 • http://www.e-publicacoes.uerj.br/index.php/polemica/index http://www.labore.uerj.br • laboreuerj@yahoo.com.br 
of conclusion and construction of analogy) aimed at understanding the coherence of its logics by means of illustrative examples.

Keywords: Social media. Social thought. Communication. Mobilization.

\section{Introdução}

O objetivo deste artigo é ilustrar a relação entre a dinâmica de geração, circulação e reprodução de conteúdos em uma rede social digital e a construção social do pensamento, com base em algumas premissas estabelecidas pela Psicologia Social, entendida como disciplina que aborda os processos de comunicação e interação entre grupos humanos.

$\mathrm{Na}$ primeira parte, apresenta-se um relato factual de três eventos que aconteceram em 2016, na Colômbia, no Reino Unido da Grã-Bretanha e no Brasil - no Estado do Rio de Janeiro, embasado em fontes que permitem entender a incidência das redes sociais digitais na forma como esses eventos se desenvolveram.

$\mathrm{Na}$ segunda parte, de corte mais analítico, aborda-se a diferença entre o pensamento lógico-racional da ciência e o pensamento social que as pessoas constroem a partir de sua interação cotidiana, extrapolando a sua lógica ao ambiente das redes sociais digitais. Finalmente, o texto retorna aos exemplos iniciais com o objetivo de ilustrar as condições de produção desse tipo de pensamento.

\section{Descrição dos fatos}

O cenário sociopolítico do primeiro exemplo a ser contemplado localiza-se na Colômbia. Em 2 de outubro de 2016, os colombianos foram chamados às urnas pelo governo do então presidente Juan Manuel Santos para endossarem, por meio de um plebiscito, um acordo de paz assinado com as Forças Armadas Revolucionárias da Colômbia (FARC), alcançado em Havana (Cuba), após três anos e nove meses de negociações.

"Você apoia o acordo geral para o fim do conflito e a construção de uma paz estável e duradoura?" foi a pergunta que os colombianos tiveram que responder com um "sim" ou um "não". Com uma abstenção de mais de 60\%, o número de votos alcançou o limiar de aprovação (13\% do censo eleitoral), mas os resultados não foram os esperados pelo governo: 6.431 .376 de colombianos votaram contra o acordo $(50,21 \%)$, enquanto 6.377 .482 o fizeram a favor

\section{POLÊM!CA $\mid$ LABORE}

Polêmica - Revista Eletrônica da Uerj - Rua São Francisco Xavier, 524, $1^{\circ}$ andar bloco D, sl.1001 • Tels.: +55 21 2334-4088 / 4087 • http://www.e-publicacoes.uerj.br/index.php/polemica/index http://www.labore.uerj.br • laboreuerj@yahoo.com.br 
$(49,78 \%)^{1}$. Essa diferença de 53.894 votos, que até surpreendeu os promotores da campanha contra o acordo, liderada especialmente pelo partido político do ex-presidente e senador Álvaro Uribe Vélez, contradisse os resultados das pesquisas de intenção de voto divulgadas na mídia e nas redes sociais digitais, que previam amplo apoio dos colombianos ao acordo de paz.

O contexto do segundo exemplo é o Reino Unido da Grã-Bretanha. Cumprindo uma promessa de campanha, o primeiro-ministro conservador David Cameron convocou um referendo para 23 de junho do 2016, por meio do qual os britânicos se pronunciariam a favor ou contra a permanência do Reino Unido na União Europeia respondendo a seguinte pergunta: "Deveria o Reino Unido permanecer como membro da União Europeia ou deveria sair da União Europeia?"2. A questão não era nova para os britânicos, uma vez que um referendo semelhante já havia sido realizado em 1975, quando uma grande maioria, apoiada por partidos políticos, sindicatos, líderes empresariais e a imprensa nacional à época, havia se manifestado a favor da permanência (MATHIESON, 2016).

Mas os resultados do referendo de 2016 não foram os mesmos: com uma porcentagem de participação de 72,2\% do censo eleitoral, 17.401 .742 de britânicos $(51,9 \%)$ votaram a favor do Brexit (acrônimo de Britain-Exit ou saída) e 16.141.241 de britânicos (48,1\%) fizeram o mesmo a favor do Bremain (acrônimo de Britain-Remain ou permanência) ${ }^{3}$, o que desencadeou a renúncia do primeiro-ministro David Cameron e a invocação do artigo 50 do Tratado de Lisboa, que estabelece os mecanismos de negociação para a saída de um Estado da União Europeia. Em 29 de março de 2017, a então primeira-ministra Theresa May o expressava nos seguintes termos perante o Parlamento:

Este é um momento histórico do qual não há como voltar atrás. A Grã-Bretanha está deixando a União Europeia. Vamos tomar as nossas próprias decisões e fazer as nossas próprias leis. Vamos assumir o controle das coisas que mais nos interessam. E vamos aproveitar esta oportunidade para construir uma Grã-Bretanha mais forte e mais justa — um país que os nossos filhos e netos possam chamar de lar com orgulho. Esse é o

\footnotetext{
${ }^{1}$ Dados fornecidos pela Registraduría Nacional del Estado Civil, órgão descentralizado do Estado colombiano encarregado da convocação e organização eleitoral desse país. Disponível em: https://www.colombia.com/elecciones/2016/plebiscito/resultados/. Acesso em: 23 fev. 2019.

${ }^{2} \mathrm{O}$ texto na língua original é: "Should the United Kingdom remain a member of the European Union or leave the European Union?".

${ }_{3}^{3}$ Dados fornecidos pela Comissão Eleitoral. Disponível em: https://www.electoralcommission.org.uk/findinformation-by-subject/elections-and-referendums/past-elections-and-referendums/eu-referendum/electorateand-count-information. Acesso em: 23 fev. 2019.
}

\section{POLÊM!CA $\mid$ LABORE}

Polêmica - Revista Eletrônica da Uerj - Rua São Francisco Xavier, 524, $1^{\circ}$ andar bloco D, sl.1001 • Tels.: +55 21 2334-4088/4087 • http://www.e-publicacoes.uerj.br/index.php/polemica/index http://www.labore.uerj.br • laboreuerj@yahoo.com.br 
nosso objetivo e a nossa oportunidade. Isso é o que este governo está determinado a fazer. (MAY, 2017, tradução nossa) ${ }^{4}$.

O terceiro exemplo ocorre no estado do Rio de Janeiro (Brasil). Em 21 de março de 2016, como parte de uma greve geral de professores estaduais, cerca de 200 jovens do Colégio Estadual Prefeito Mendes de Moraes decidiram "ocupar" sua escola como uma ação de protesto e resistência civil. Naquele mesmo dia, eles criaram uma página no Facebook e postaram a seguinte mensagem: "Alunos do Colégio Estadual Prefeito Mendes de Moraes ocuparam hoje a escola em resposta à forte opressão da direção e da SEEDUC [Secretaria Estadual de Educação]".

Figura - 1: Primeira postagem da ocupação das escolas do Rio de Janeiro (2016)

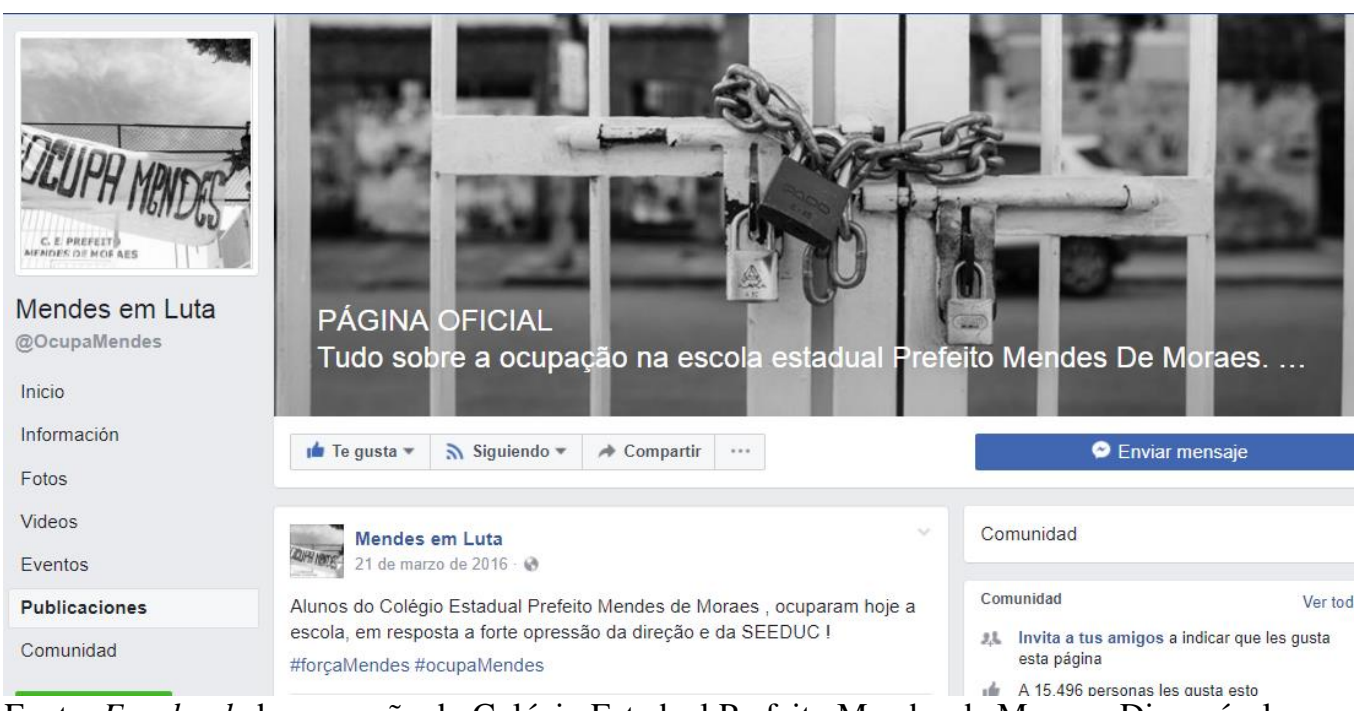

Fonte: Facebook da ocupação do Colégio Estadual Prefeito Mendes de Moraes. Disponível em: https://web.facebook.com/OcupaMendes/posts/241381122882574.

Um evento semelhante de ocupação de escolas estaduais já tinha acontecido no estado de São Paulo havia dois meses, quando aproximadamente 200 escolas foram ocupadas por estudantes durante dois meses, como uma forma de pressão para que o governo revertesse um plano de reorganização e redistribuição das vagas escolares nesse estado da região Sudeste do Brasil. No Rio de Janeiro, o que começou como uma ação isolada de uma escola, aos poucos

\footnotetext{
${ }^{4} \mathrm{O}$ texto na língua original é: "This is an historic moment from which there can be no turning back. Britain is leaving the European Union. We are going to make our own decisions and our own laws. We are going to take control of the things that matter most to us. And we are going to take this opportunity to build a stronger, fairer Britain - a country that our children and grandchildren are proud to call home. That is our ambition and our opportunity. That is what this government is determined to do" (MAY, 2017).
}

\section{POLÊM!CA $\mid$ LABORE}

Polêmica - Revista Eletrônica da Uerj - Rua São Francisco Xavier, 524, $1^{\circ}$ andar bloco D, sl.1001 • Tels.: +55 21 2334-4088 / 4087 • http://www.e-publicacoes.uerj.br/index.php/polemica/index http://www.labore.uerj.br • laboreuerj@yahoo.com.br 
tornou-se um movimento de ocupação estudantil, que envolveu aproximadamente 80 escolas em todo o Estado e que terminou em $1^{\circ}$ de junho de 2016, quando a Juíza Titular da $2^{\circ}$ Vara de Infância e Adolescência ordenou o retorno às aulas.

Em decorrência dessa ação coletiva de protesto, que aconteceu tanto nos espaços físicos das escolas quanto nas redes sociais digitais - cada escola tinha uma página no Facebook que funcionava como nó de uma rede -, a Secretaria Estadual de Educação se viu obrigada a negociar com os estudantes uma pauta de reinvindicações específicas de cada escola, além de autorizar a eleição democrática dos diretores e a reformulação do Sistema de Avaliação da Educação do Estado (SAERJ).

\section{Interpretação dos acontecimentos}

Embora o contexto histórico e sociopolítico de cada um dos três fatos supracitados seja diferente, há um elemento comum entre eles que permite abordar o conceito de geração, circulação e reprodução do pensamento social: trata-se das redes sociais digitais como ambiente aberto de construção e legitimação de narrativas, que determinaram os resultados desses eventos. A seguir, far-se-á uma análise da forma como aconteceu cada fato com o propósito de entender a sua dinâmica comunicacional.

Em 24 de agosto de 2016, o governo da Colômbia e as FARC apresentaram o "Acordo geral para o fim do conflito e a construção de uma paz estável e duradoura" (ALTO COMISIONADO PARA LA PAZ, 2016): um documento de 227 páginas, que continha os acordos alcançados durante os quase quatro anos de negociações, o que interpretava-se como a possibilidade de que um dos atores armados, que tinha sido protagonista da história da guerra recente naquele país, deixasse as armas e abraçasse a ordem constitucional democrática. De acordo com o Centro Nacional de Memória Histórica $(\mathrm{CNMH})^{5}$, entre 1958 e 2012, aproximadamente 220 mil morreram por causa das ações dos atores armados (guerrilhas, paramilitares e forças do Estado) no quadro do conflito colombiano; o mesmo órgão também faz referência a 25.000 pessoas desaparecidas e 4,7 milhões de deslocadas (CNMH, 2016).

O acordo final foi construído em torno de seis questões fundamentais: 1) reforma rural integral, 2) participação política do grupo insurgente, 3) cessar-fogo bilateral e abandono de

\footnotetext{
${ }^{5}$ O Centro Nacional de Memória Histórica é uma instituição governamental, criada a partir da Lei 1.148 de 2011, conhecida na Colômbia como a Lei de Vítimas e Restituição de Terras.
}

\section{POLÊM!CA $\mid$ LABORE}

Polêmica - Revista Eletrônica da Uerj - Rua São Francisco Xavier, 524, $1^{\circ}$ andar bloco D, sl.1001 • Tels.: +55 21 2334-4088/4087 • http://www.e-publicacoes.uerj.br/index.php/polemica/index http://www.labore.uerj.br • laboreuerj@yahoo.com.br 
armas, 4) drogas ilícitas, 5) compensação às vítimas e 6) mecanismos de implementação e verificação dos acordos.

Durante o período transcorrido entre a apresentação do acordo (24 de agosto) e o plebiscito ( 2 de outubro), tanto defensores como opositores realizaram suas respectivas campanhas, que concluíram com os resultados mencionados no início deste texto: o "não" derrotou o "sim" por pouco mais de 50 mil votos, criando um dos momentos de maior incerteza na história contemporânea da Colômbia.

Dois dias após a apuração dos resultados, o gerente da campanha contra o acordo, Juan Carlos Vélez, em entrevista à jornalista Juliana Ramírez do jornal La República, referiu-se à estratégia utilizada pela sua campanha. A jornalista perguntou: "A campanha a favor do acordo esteve baseada na esperança de um novo país; qual foi a mensagem da campanha de vocês?" O político respondeu: "A indignação. Queríamos que o pessoal fosse às urnas votar verraco" (RAMÍREZ, 2016). O líder político explicou para a jornalista como foi a estratégia comunicacional da campanha contra o acordo de paz:

A gente descobriu o poder viral das redes sociais. Por exemplo, em uma visita a Apartadó [Noroeste da Colômbia] um vereador compartilhou comigo uma foto do Presidente Santos e Timoshenko com uma legenda que questionava por que o presidente iria dar dinheiro para os guerrilheiros se o país estava falido. Eu postei essa foto no meu Facebook e no sábado passado tinha 130.000 compartilhamentos [...] Alguns estrategistas do Panamá e do Brasil nos disseram que a estratégia era parar de explicar os acordos e centrar a mensagem na indignação. Nas emissoras de rádio orientadas a camadas de meia e alta renda nós nos enfocamos na rejeição à impunidade, na elegibilidade dos guerrilheiros e na reforma tributária, enquanto nas emissoras dirigidas a camadas de mais baixa renda nós nos concentramos nos subsídios aos guerrilheiros [...] no litoral Caribe reforçamos a mensagem que a Colômbia viraria uma Venezuela. Em oito municípios de Cauca [uma região da Colombia onde a guerra foi particularmente crua] nos focamos na voz das vítimas. A campanha contra o acordo venceu sem pagar um conto. (RAMÍREZ, 2016, grifo nosso).

A expressão "parar de explicar os acordos e centrar a mensagem na indignação" mostra que a estratégia dos opositores apelou para o sentimento dos eleitores, criando do ponto de vista lógico uma relação aparentemente coerente entre eventos reais e falsas consequências.

A aproximação da dinâmica comunicacional nas redes sociais digitais das campanhas a favor da saída ou permanência do Reino Unido na União Europeia, mostra uma realidade semelhante ao caso do plebiscito colombiano, também caracterizada pela predominância de

\footnotetext{
${ }^{6} \mathrm{Na}$ Colômbia, esse adjetivo coloquial é usado para se referir, entre outros significados, a uma pessoa que está com muita raiva.

\section{POLÊM!CA $\mid$ LABORE}

Polêmica - Revista Eletrônica da Uerj - Rua São Francisco Xavier, 524, $1^{\circ}$ andar bloco D, sl.1001 • Tels.: +55 21 2334-4088/4087 • http://www.e-publicacoes.uerj.br/index.php/polemica/index http://www.labore.uerj.br • laboreuerj@yahoo.com.br
} 
conteúdos que privilegiam a emoção (Figura 2). No entanto, quando argumentos racionais e econômicos apareceram a favor da saída, por exemplo, foram usadas informações distorcidas e tendenciosas, como aquela segundo a qual custava ao Reino Unido 350 milhões de libras esterlinas por semana a sua permanência na União Europeia (THE ECONOMIST, 2016).

Figura - 2: Postagem do Instagram mais comentada na campanha do Brexit
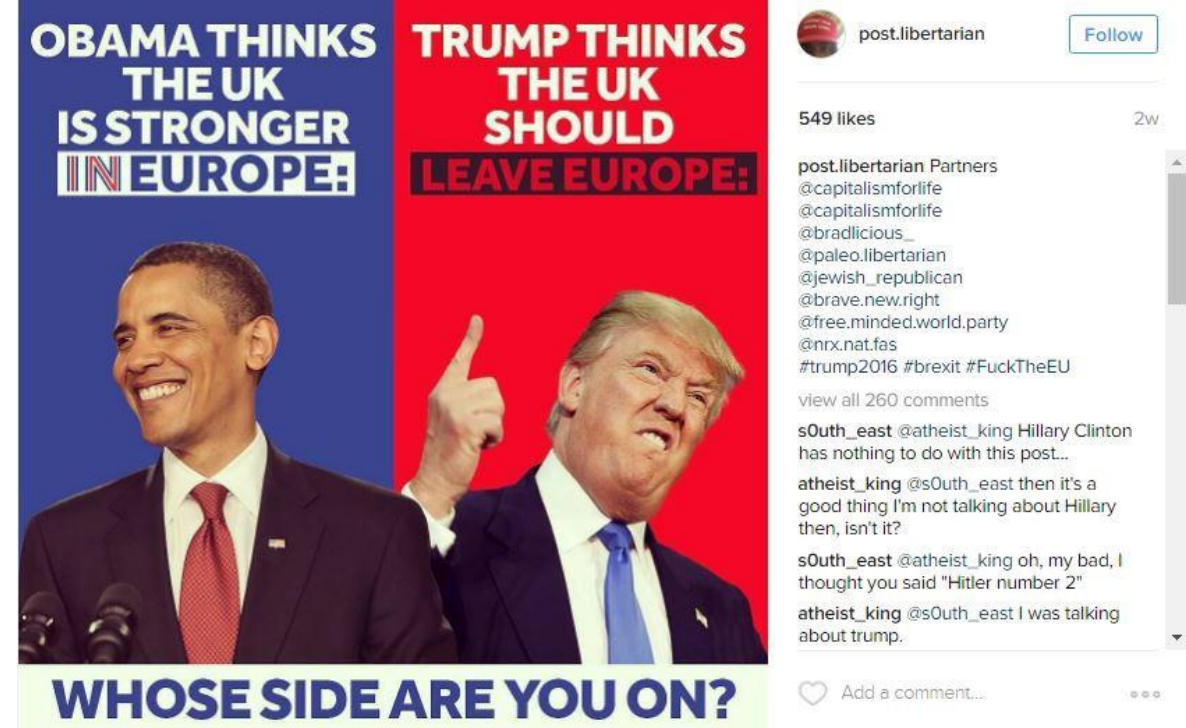

Fonte: Blog Medium (POLONSKI, 2016a).

A verdade é que a contundência com que a mensagem ${ }^{7}$ foi divulgada pelos promotores da saída (leavers) fez com que os eleitores indecisos apontassem a balança a favor do Brexit, como explicam as análises publicadas por Polonski (2016b), do Instituto de Internet de Oxford:

\begin{abstract}
O sentimento avassalador do Leave [campanha a favor da saída] nas redes sociais era consistente e inegável, embora muitos seguidores do Remain [campanha a favor da permanência] optassem por ignorar a voz da Internet como algo que não tinha conexão com o mundo político real. Eles acreditavam que a Grã-Bretanha nunca votaria a favor da saída da União Europeia e descartaram as redes sociais como se fosse apenas um parque de diversões para trolls ${ }^{8}$ e adolescentes. (POLONSKI, 2016b, tradução nossa).
\end{abstract}

Foi precisamente a partir desses resultados e da forma como a campanha de Donald Trump para presidente dos Estados Unidos se desenvolveu nas redes sociais digitais, que o

\footnotetext{
${ }^{7} \mathrm{O}$ Instituto de Internet de Oxford utiliza os adjetivos intuitive (intuitivo) e straightforward (direto, simples) para se referir a esse tipo de comunicação (POLONSKI, 2016b)

${ }^{8} \mathrm{Na}$ linguagem da Internet, o troll é o internauta que publica mensagens provocadoras em redes sociais ou fóruns virtuais, gerando uma reação de rejeição ou aborrecimento nos participantes.
}

\title{
POLÊM!CA $\mid$ LABORE (
}

Polêmica - Revista Eletrônica da Uerj - Rua São Francisco Xavier, 524, $1^{\circ}$ andar bloco D, sl.1001 • Tels.: +55 21 2334-4088 / 4087 • http://www.e-publicacoes.uerj.br/index.php/polemica/index http://www.labore.uerj.br • laboreuerj@yahoo.com.br 
editorial da revista The Economist de 10 de setembro de 2016 fez a seguinte radiografia: "as mentiras que são amplamente compartilhadas on-line dentro de uma rede, cujos membros confiam uns nos outros mais do que em qualquer fonte de meios convencionais, pode assumir rapidamente a aparência de verdade" (THE ECONOMIST, 2016, tradução nossa).

O editorial estava se referindo a um termo que dois meses depois teria de ser escolhido pelo dicionário Oxford como a palavra do ano: pós-verdade (post-truth em inglês), definindoa como um termo relacionado às "circunstâncias nas quais os fatos objetivos têm menos influência na opinião pública do que o apelo à emoção e à crença pessoal" (OXFORD DICTIONARY, 2016).

Por fim, no que diz respeito à ocupação das escolas do Rio de Janeiro por parte de estudantes secundaristas, é importante frisar que embora seja um fenômeno cuja dinâmica comunicacional difere do processo eleitoral na Colômbia e no Reino Unido, compartilha com eles uma característica fundamental: a centralidade da emoção no processo de construção e reprodução de mensagens por meio das redes sociais digitais.

Em estudo anterior, após a realização de uma análise de conteúdo de 250 postagens extraídas das páginas do Facebook de 35 escolas ocupadas (ECHEVERRI; WOLTER; PEIXOTO, 2019), que foram segmentadas em unidades de registro e agrupadas em focos semânticos ou categorias, foi possível inferir que apesar de ser uma ação de pressão direta, que buscava gerar maior atenção do Estado às exigências específicas dos alunos em relação à precariedade das condições da educação pública, não foi esse o foco semântico das postagens mais curtidas, compartilhadas ou comentadas.

\section{POLÊM!CA LABORE}


Figura - 3: Comparação de categorias semânticas segundo critérios de share/engagement

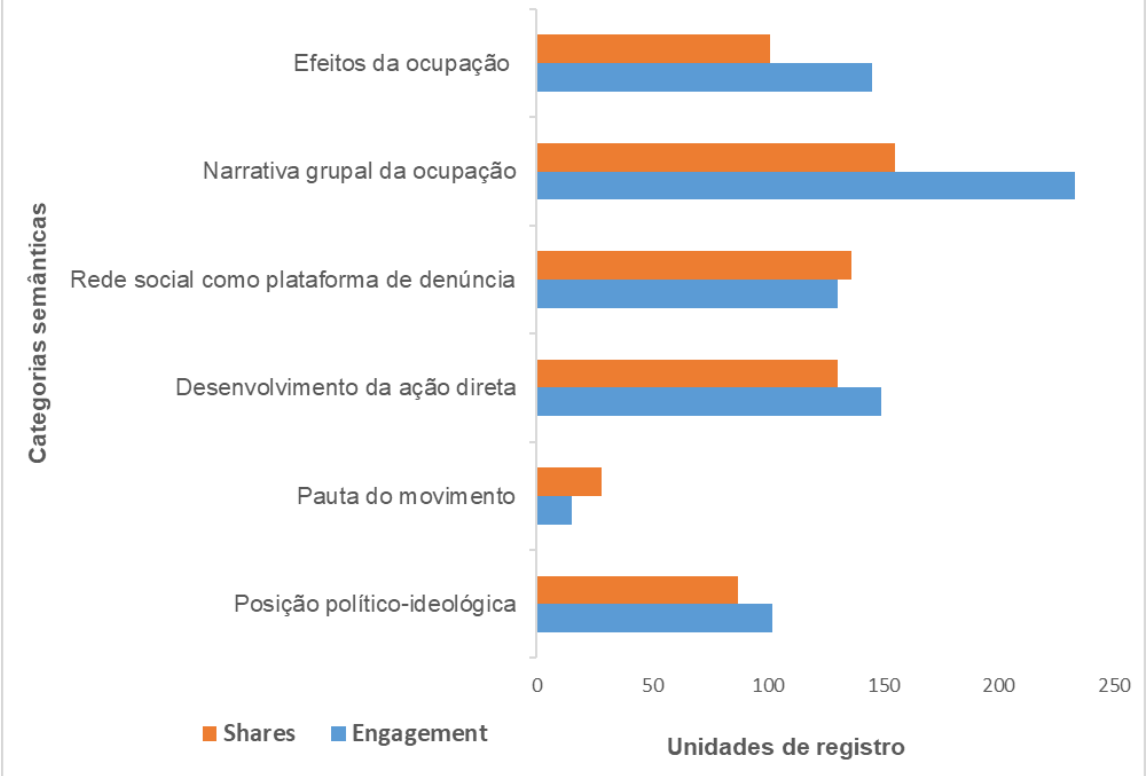

Fonte: ECHEVERRI; WOLTER; PEIXOTO, 2019.

É importante apontar que a Figura 3 compara o número de unidades de registro correspondentes às publicações compartilhadas (shares) com o número de unidades de registro segundo o seu engagement (engajamento). Na linguagem das redes sociais, o engajamento é calculado por meio da soma das curtidas (likes) e os comentários (comments). Geralmente, optase por separar ambos os critérios, já que a ação de "compartilhar" é ilimitada (um único usuário pode fazê-lo quantas vezes quiser), enquanto a ação de "curtir" apenas pode ser feita uma só vez. Em termos do impacto de um conteúdo no contexto de uma rede, o engajamento fornece mais informações do que o primeiro.

Nessa ordem de ideias, prevaleceu o conteúdo relacionado à narrativa grupal da ocupação, ou seja, o modo como os estudantes viam e descreviam a si próprios como "lutadores/guerreiros" que continuavam a ocupar suas escolas apesar das circunstâncias, não desistindo perante um "Estado repressor", elemento que não foi difundido pela mídia corporativa tradicional. Por outras palavras, as "ocupas" construíram e legitimaram na sua rede de comunicação, uma narrativa de interpretação da ocupação com um marcado viés afetivo.

Portanto, não é de surpreender que a postagem mais compartilhada no quadro dessa rede (3.042 vezes) tenha sido a fotografia de um jovem deitado na rua, à noite, com uma substância branca no rosto (possivelmente resíduos de gás lacrimogêneo), sendo auxiliado por uma estudante aparentemente desesperada e nervosa; a imagem é acompanhada da seguinte legenda:

\section{POLÊM!CA $\mid$ LABORE}

Polêmica - Revista Eletrônica da Uerj - Rua São Francisco Xavier, 524, $1^{\circ}$ andar bloco D, sl.1001 • Tels.: +55 21 2334-4088 / 4087 • http://www.e-publicacoes.uerj.br/index.php/polemica/index http://www.labore.uerj.br • laboreuerj@yahoo.com.br 
"A tropa de choque acaba de espancar alunos do Ocupa Mendes e outros alunos que ocupavam a SEEDUC. Alunos desmaiados e feridos no local!"9.

\title{
A sociedade como sistema de pensamento
}

O fato de as redes sociais digitais estarem contribuindo para a configuração de uma nova morfologia do espaço público (CASTELLS, 2013) é uma realidade irrefutável. Ao se enfocar na gênese da esfera do público no Ocidente, atrelada ao crescimento do capitalismo e a burguesia europeia em fins do século XVII e alvores do século XVIII, é comum achar referências às casas de café de Londres, os salões de Paris e as Tischgessellschaften ou sociedades de mesa da Alemanha (PRICE, 1992). As ideias que dali emanavam, na forma de manifestos impressos ou da incipiente imprensa escrita, aos poucos iriam pavimentando o caminho para mudanças políticas em sociedades assaz convulsas.

Hoje, mais de trezentos anos depois, com a consolidação gradual da Internet como ferramenta que facilita o acesso e a troca de informações em tempo real, é possível se deparar com um dispositivo revolucionário que mudou, dentre outros aspectos, a forma como grupos humanos se comunicam e se relacionam com "o público", possibilitando o surgimento de narrativas múltiplas sobre um mesmo evento.

\begin{abstract}
À diferença da narrativa jornalística, marcada pela autenticação dos fatos, hierarquização de fontes, predomínio do passado, busca de uma enunciação à distância do fato narrado e repetição de versões únicas, a narrativa colaborativa $P 2 P$ [entre iguais] é o relato feito por uma multiplicidade de perfis na Internet que portam o tempo da linha do tempo como um agora, assumem uma franqueza no falar como valor e regra para se alcançar a verdade, identificam-se como sujeitos unidos ao acontecimento, atores de sua atualização, e têm a republicação como estratégia de alargamento de si e de sua própria potência em uma audiência intensa (MALINI; ANTOUN, 2013, p. 198, grifos nossos).
\end{abstract}

Contudo, a construção de uma narrativa está ligada à formação do pensamento e esse é precisamente o foco do presente artigo. Serge Moscovici (1925-2014), uma das figuras mais emblemáticas da Psicologia Social europeia, cuja Teoria das Representações Sociais teve grande aceitação e impacto na América Latina, afirmou que, assim como uma sociedade pode ser concebida como um sistema político ou econômico, também pode ser entendida como um sistema de pensamento (MOSCOVICI, 1989). Dentro desse sistema coexistem, segundo o

\footnotetext{
${ }^{9}$ Note-se que é usado o verbo "espancar", que possui uma conotação de abuso excessivo da força. Disponível em: https://web.facebook.com/OcupaMendes/posts/278076315879721. Acesso em: 23 fev. 2019.
}

\section{POLÊM!CA | LABORE.}

Polêmica - Revista Eletrônica da Uerj - Rua São Francisco Xavier, 524, $1^{\circ}$ andar bloco D, sl.1001 • Tels.: +55 21 2334-4088 / 4087 • http://www.e-publicacoes.uerj.br/index.php/polemica/index http://www.labore.uerj.br • laboreuerj@yahoo.com.br 
cientista romeno, dois universos: o universo do pensamento reificado e o universo do pensamento consensual.

[No universo reificado] se produzem e circulam as ciências e o pensamento erudito em geral, com sua objetividade, seu rigor lógico e metodológico, sua teorização abstrata, sua compartimentalização e sua especialização hierárquica. Aos universos consensuais correspondem as atividades intelectuais da interação social cotidiana pelas quais são produzidas as representações sociais (SÁ, 2015, p. 192).

Essas representações sociais, construídas a partir da "arte da conversação" na interação cotidiana, foram denominadas por Moscovici como "verdadeiras teorias do senso comum, 'ciências coletivas' sui generis, pelas quais se procede à interpretação e mesmo à construção das realidades sociais" (SÁ, 2015, p. 190).

\begin{abstract}
A teoria das representações sociais pretende ser uma recuperação da dimensão social e simbólica do conhecimento como objeto de estudo da psicologia social. As representações sociais compartilham, portanto, três características fundamentais: sua formação na interação social, o fato de serem sempre representações de algo ou de alguém e, finalmente, terem um caráter simbólico (ÁLVARO; GARRIDO, 2006, p. 288).
\end{abstract}

Ora, os objetos sobre os quais os grupos humanos criam uma representação social no universo consensual, geralmente, provêm do universo reificado e Moscovici o comprovou com seu estudo da psicanálise como um fato social na França em fins da década de 1950 (MOSCOVICI, 1961). A partir de um método que incluiu, dentre outras técnicas, a análise de conteúdo de 230 revistas e jornais franceses, Moscovici descobriu que a mídia operava a partir de três lógicas interpretativas diferentes: enquanto a grande mídia impressa disseminava informações sobre a psicanálise agindo como reprodutora da voz dos especialistas e mantendo uma distância do objeto (lógica da difusão), a mídia reconhecida como católica acomodava e integrava os conceitos freudianos ao pensamento grupal, omitindo alusões a conteúdos relacionados à sexualidade (lógica da propagação); e a mídia da esquerda comunista, por sua vez, operava sob a lógica do antagonismo, rotulando a psicanálise de "ciência burguesa" (lógica da propaganda).

A teoria geral das representações sociais ${ }^{10}$ abriu o caminho para compreender e estudar o que é o pensamento social, entendido como o pensamento cotidiano que se expressa nas

\footnotetext{
${ }^{10}$ É importante destacar outras teorias complementares, como a do núcleo central (ABRIC, 1994) que contribuíram para o estudo da formação e transformação das representações sociais.
}

\title{
POLÊM!CA $\mid$ LABORE
}

Polêmica - Revista Eletrônica da Uerj - Rua São Francisco Xavier, 524, $1^{\circ}$ andar bloco D, sl.1001 • Tels.: +55 21 2334-4088/4087 • http://www.e-publicacoes.uerj.br/index.php/polemica/index http://www.labore.uerj.br • laboreuerj@yahoo.com.br 
conversações, na evocação das lembranças, na transmissão dos rumores e na euforia das multidões (ROUQUETTE, 1996; 1998), e que se diferencia do pensamento científico-racional, caracterizado por quatro características essenciais: "a lógica canônica do raciocínio; a submissão à evidência dos fatos; a existência de forte regulação institucional; e a exigência de reprodutibilidade "(ROUQUETTE, 2009, p. 5).

No início do texto, ao apresentar o objetivo de abordar a forma como se gera o pensamento social no âmbito das redes sociais digitais, se levou em consideração a possibilidade de associar esse processo ao conceito de "arquitetura do pensamento social", que Rouquette propôs em 1973 para integrar, de forma hierárquica, as diferentes formas desse tipo de pensamento, segundo dois princípios ou critérios: estabilidade e integração, como mostra a Figura 4.

Figura - 4: Arquitetura do pensamento social segundo Rouquette (2009)

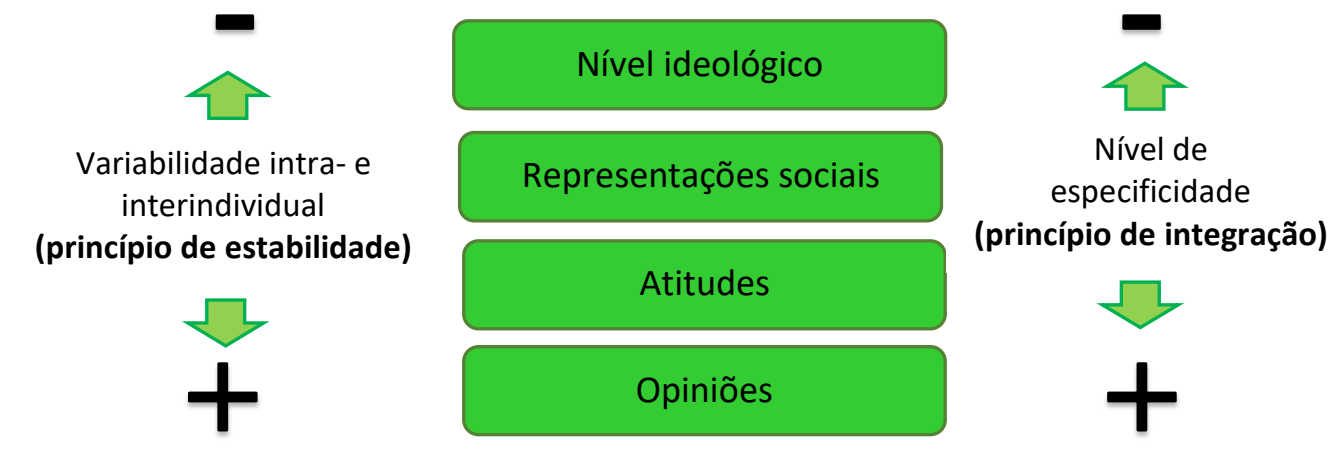

Fonte: ROUQUETTE (2009).

Segundo Rouquette (2009), a razão dessa hierarquia seria a relação lógica e geradora (reprodutora para ser mais precisos), que permite escalar os diferentes níveis: as atitudes permitem dar conta das opiniões; as representações, fundadoras de uma cultura ou subcultura, dão conta das atitudes; e os componentes ideológicos, ainda mais gerais e compartilhados, são os que permitem "construir" representações sociais, entendidas como conjunto de crenças gerais, valores e modelos epistêmicos. $\mathrm{O}$ autor explica que, do ponto de vista histórico, é possível atravessar essa hierarquia ao passar de expressões instantâneas ou momentâneas do pensamento social a outras construções mais estáveis no tempo, próprias de conjuntos sociais maiores.

\section{POLÊM!CA $\mid$ LABORË}

Polêmica - Revista Eletrônica da Uerj - Rua São Francisco Xavier, 524, $1^{\circ}$ andar bloco D, sl.1001 • Tels.: +55 21 2334-4088 / 4087 • http://www.e-publicacoes.uerj.br/index.php/polemica/index http://www.labore.uerj.br • laboreuerj@yahoo.com.br 
Como explicado por Wolter (2008) e Wolter et al (2009), os princípios da estabilidade e da integração são entendidos como um continuum que vai da extrema estabilidade à instabilidade total e do mais específico ao mais geral. Dessa forma, é possível fazer referência às opiniões como as formas mais instáveis e específicas do pensamento social, enquanto a ideologia se caracterizaria por ser mais geral e estável ao longo da história.

Daí que, por exemplo, ao extrapolar ambos os princípios ao processo de visualização de dados procedentes de uma rede social digital (por meio de qualquer software que permita a utilização de grafos), seja possível conferir que a formação de nós e a criação de clusters (associações baseadas em atributos de cor) esteja relacionada aos princípios de maior instabilidade e contingência da arquitetura, isto é, as opiniões e as atitudes, a partir dos quais criam-se as narrativas. No entanto, a desconstrução cuidadosa dessas narrativas ou formas de contar os fatos pode levar à descoberta de formas mais estáveis de interpretação (representações sociais), que Guimelli (1999) define como metassistemas, cuja função seria canalizar, modificar e orientar as operações cognitivas, a partir dos modelos, crenças e valores de um grupo.

\section{Condições de produção do pensamento social}

Partindo do conceito de metassistema como forma estável de interpretação, é importante concentrar a atenção em quatro elementos que Guimelli (1999) denomina condições de produção do pensamento social, aspectos que o tornam consistente e que o diferenciam da lógica do pensamento científico-racional. O autor refere-se ao formalismo espontâneo, o dualismo causal, a primazia da conclusão e a construção de analogia, que podem ser explicados e exemplificados a partir dos três fatos históricos citados ao longo do presente texto.

Ao fazer alusão ao formalismo espontâneo, se faz referência à repetição de automatismos, estereótipos linguísticos e clichês em torno de um tópico específico. "Castrochavismo", "essa ai é a paz do Santos [presidente que assinou o acordo]" e "entregar o país às $F A R C^{\prime \prime}$ são exemplos do formalismo espontâneo que circularam nas redes sociais digitais e que estiveram presentes nos conteúdos relacionados ao plebiscito colombiano. Já no caso da ocupação das escolas do Rio de Janeiro, encontram-se palavras de ordem como "ocupar, resistir, lutar pra garantir", "pisa ligeiro, pisa ligeiro, quem não pode com formiga não atiça o

\section{POLÊM!CA $\mid$ LABORE}

Polêmica - Revista Eletrônica da Uerj - Rua São Francisco Xavier, 524, $1^{\circ}$ andar bloco D, sl.1001 • Tels.: +55 21 2334-4088/4087 • http://www.e-publicacoes.uerj.br/index.php/polemica/index http://www.labore.uerj.br • laboreuerj@yahoo.com.br 
formigueiro" ${ }^{11}$, que eram entoadas pelos estudantes como desafio aos funcionários da Secretaria Estadual de Educação, assim como o uso da hashtag \#ocupatudo.

Cabe apontar aqui que as hashtags ou rótulos são uma marca do formalismo espontâneo próprio da linguagem das redes sociais digitais, entendida como "uma espécie de Napster"12 da narrativa noticiosa, em que os internautas têm acesso a tudo o que se publica na rede, de forma direta, ponto a ponto, de baixo para cima, criando e participando de um grande mural conversacional e de uma comunidade virtual da notícia" (MALINI; ANTOUN, 2013, p. 188).

O dualismo causal é definido por Guimelli (1999) como a coexistência de dois tipos de relação de causa-efeito: a primeira, que provém do pensamento lógico-racional (a causa é condição necessária para a geração de um efeito) e a segunda, de tipo fenomênico, que permite inferir que um evento é causa de outro, partindo de sua proximidade, simultaneidade, semelhança ou, simplesmente, da intenção do grupo que acomoda o raciocínio a seu quadro de referência.

A forma como alguns grupos cristãos conservadores na Colômbia associaram a palavra gênero, expressa 113 vezes no acordo assinado em Havana ${ }^{13}$, a uma estratégia velada para a implantação e legitimação constitucional da "ideologia de gênero" nas escolas de todo o país, é um exemplo que permite ilustrar o dualismo causal. É importante lembrar que apenas dois meses antes do plebiscito, esses grupos tinham se pronunciado nas redes sociais digitais e na mídia corporativa tradicional contra os rascunhos de umas cartilhas que o Ministério de Educação Nacional, cumprindo um mandado constitucional ${ }^{14}$, teria de entregar nas escolas, visando a revisão dos manuais de convivência escolar. A publicação desse rascunho, que fazia alusão ao gênero como uma construção cultural, gerou pronunciamentos de rejeição como o da

\footnotetext{
${ }^{11}$ Frase que tornou-se famosa e conhecida a partir do documentário sobre os indígenas Xucuru-Kariri, e que o Movimento dos Sem-Terra (MST) do Brasil usa com frequência. O documentário está disponível em: https://www.youtube.com/watch?v=pA3FsWwPZGY. Acesso em: 23 fev. 2019.

12 A palavra Napster refere-se ao programa que permitia compartilhar e baixar livremente arquivos de música MP3 de maneira descentralizada; isto é, cada computador conectado à rede era simultaneamente servidor e usuário dos conteúdos musicais.

${ }^{13}$ García (2016), após fazer uma análise do termo gênero no conteúdo das 297 páginas do acordo final, constatou que a palavra surgiu 113 vezes, relacionando-se a diversos focos semânticos, tais como abordagem diferencial entre vítimas homens e mulheres, política pública diferenciada de empoderamento para mulheres, tipos de violências. O conceito "identidade de gênero", por sua vez, é apenas mencionado sete vezes ao longo do texto.

${ }^{14}$ Sentença T-478 de 2015 do Tribunal Constitucional da Colômbia sobre discriminação baseada na orientação sexual e identidade de gênero em ambientes escolares. Disponível em: http://www.corteconstitucional.gov.co/inicio/T-478-15\%20ExpT4734501\%20(Sergio\%20Urrego).pdf. Acesso em: 23 fev. 2019.
}

\section{POLÊM!CA $\mid$ LABORE}

Polêmica - Revista Eletrônica da Uerj - Rua São Francisco Xavier, 524, $1^{\circ}$ andar bloco D, sl.1001 • Tels.: +55 21 2334-4088 / 4087 • http://www.e-publicacoes.uerj.br/index.php/polemica/index http://www.labore.uerj.br • laboreuerj@yahoo.com.br 
Conferência dos Bispos da Colômbia ${ }^{15}$ e mobilizações de protesto em várias cidades do país.

A interpretação que estes grupos conservadores fizeram da palavra "gênero" pode ter sido um dos fatores que incidiram no resultado do plebiscito dois meses mais tarde, especialmente ao levar em consideração que a ministra da Educação à época, abertamente lésbica, tinha sido a funcionária escolhida pelo governo nacional para liderar a campanha a favor do acordo de paz. Do ponto de vista do pensamento lógico-racional, poder-se-ia falar em eventos sem aparente conexão (orientação sexual da ministra, rascunhos de cartilhas escolares sobre orientação sexual e identidade de gênero, alusão à palavra gênero no acordo de paz), que a lógica do pensamento social simplifica e integra a modo de cadeia causal, atribuindo a um raciocínio falacioso uma condição de verdade que não possui.

A terceira condição de produção do pensamento social, que Guimelli (1999) denominou primazia da conclusão, refere-se a uma forma de raciocínio segundo a qual, partindo de uma conclusão, um grupo seleciona e acomoda elementos de informação de acordo com as suas preferências, crenças ou valores, privilegiando a justificativa em detrimento da argumentação e a demonstração. Um exemplo ilustrativo da maneira pela qual a primazia da conclusão é ativada no ambiente das redes sociais digitais encontra-se na ocupação das escolas públicas por parte dos estudantes secundaristas do Rio de Janeiro. Em 20 de abril de 2016, um mês após o início da ocupação, a Secretaria Estadual de Educação postou uma mensagem no Twitter oficial informando o lugar e a hora de uma passeata a favor da desocupação, se utilizando da hashtag \#NãoOcupa ${ }^{16}$. A partir de então, a narrativa dos "ocupas" girou em torno de um suposto plano sistemático, forjado entre a Secretaria Estadual de Educação e os "desocupas" para forçar a desocupação, em conluio com a Polícia Militar.

Finalmente, a quarta condição de produção do pensamento social é a analogia, que Guimelli (1999) considera o centro da atividade cognitiva que organiza o pensamento social. Trata-se de um processo de economia da informação, que parte da atribuição de propriedades características de um objeto $\mathrm{Y}$ a um objeto $\mathrm{X}$ e que contribui para a simplificação do real, o que

\footnotetext{
${ }^{15}$ Comunicado da Conferência de Bispos da Colômbia criticando as diretrizes do Ministério da Educação sobre os manuais de convivência escolar. Disponível em:

https://www.cec.org.co/sites/default/files/Comunicado\%20Orientaciones\%20Ministerior\%20Educacio\%CC\%81 n.pdf. Acesso em: 23 fev. 2019.

${ }^{16}$ Disponível em:

https://web.facebook.com/OcupaMendes/photos/a.241383286215691.1073741828.241377779549575/27293622 3060397/?type $=3 \&$ theater. Acesso em: 23 fev. 2019.
}

\section{POLÊM!CA $\mid$ LABORE}

Polêmica - Revista Eletrônica da Uerj - Rua São Francisco Xavier, 524, $1^{\circ}$ andar bloco D, sl.1001 • Tels.: +55 21 2334-4088/4087 • http://www.e-publicacoes.uerj.br/index.php/polemica/index http://www.labore.uerj.br • laboreuerj@yahoo.com.br 
não é infrequente no ambiente das redes sociais digitais. A publicação mais comentada do Instagram durante a campanha do Brexit (Figura 2), na qual aparece Barack Obama apoiando a campanha do Remain (permanecer na União Europeia) e o então candidato à presidência dos Estados Unidos, Donald Trump, apoiando a campanha do Leave (sair da União Europeia), é ilustrativa o suficiente e pode ser interpretada como a visão que os remainers (conservadores, associados à cor azul) têm sobre os leavers (associados à cor vermelha do partido trabalhista) como pessoas impulsivas, que não pensam nas consequências de suas ações.

Outro exemplo de analogia que se tornou viral durante a ocupação das escolas no Rio de Janeiro foi a versão alemã, legendada em português, de uma cena do filme Der Untergang ${ }^{17}$, na qual Hitler discute com seus tenentes no bunker durante a Batalha de Berlim. Na paródia da ocupação, que também foi utilizada pelos estudantes de São Paulo, Hitler interpreta o secretário de Educação do Rio de Janeiro, que reage com fúria aos avanços aparentemente irreprimíveis de um movimento de estudantes que ocupam as escolas nos quatro cantos do Estado ${ }^{18}$.

\section{Conclusão}

O Relatório Digital News do Instituto Reuters e a Universidade de Oxford (LEVY et al, 2017), elaborado a partir de uma pesquisa com 70 mil pessoas, em 36 países (Argentina, Brasil, Chile e México, entre eles), sobre o consumo de informação noticiosa, revela um dado muito interessante e esclarecedor, que apoia a análise abordada no presente texto: $33 \%$ dos jovens entre 18 e 24 anos acessam às notícias apenas por meio das redes sociais digitais e $64 \%$ o fazem on-line, o que também pode incluir esses dispositivos ${ }^{19}$.

Esse achado confirma a afirmação de Lazzarato (2006), segundo a qual a Internet não é apenas um dispositivo de formação da opinião pública, mas a possibilidade de construção de "uma forma de percepção comum e formas de organização e expressão da inteligência comum" (MALINI, ANTOUN, 2013, p. 183). O artigo, justamente, concentrou-se em dar-lhe uma dimensão maior, do ponto de vista da psicologia social, ao que o filósofo italiano chama de

\footnotetext{
${ }^{17} \mathrm{O}$ filme, dirigido por Oliver Hirschbiegel, foi lançado em 2004 e ficou conhecido como El Hundimiento na Espanha, La Caída nos países de língua espanhola da América Latina e A Queda no Brasil.

${ }^{18} \mathrm{O}$ vídeo da paródia está disponível em: <https://www.youtube.com/watch?v=XMxmQUZRt8U>. Acesso em: 23 fev. 2019.

${ }^{19}$ A pergunta formulada foi a seguinte: Você nos disse que usou as seguintes fontes de notícias na última semana (Internet incluindo redes sociais, rádio, imprensa escrita e televisão). O que você diria que é a sua principal fonte de notícias? (LEVY et al., 2016, p. 10).
}

\section{POLÊM!CA $\mid$ LABORE}

Polêmica - Revista Eletrônica da Uerj - Rua São Francisco Xavier, 524, $1^{\circ}$ andar bloco D, sl.1001 • Tels.: +55 21 2334-4088/4087 • http://www.e-publicacoes.uerj.br/index.php/polemica/index http://www.labore.uerj.br • laboreuerj@yahoo.com.br 
"comum", abrindo o horizonte de análise para o pensamento social construído a partir da interação comunicacional cotidiana.

Ao extrapolar os princípios de estabilidade e integração a uma rede de troca de informação, é possível confirmar que a "arquitetura" proposta por Rouquette (2009) é um modelo teórico explicativo que ajuda a entender a forma como se geram as diferentes modalidades do pensamento social e sua inter-relação, da mais contingente e lábil, como a opinião, até a mais geral e estável, como a ideologia.

Finalmente, através de exemplos ilustrativos relacionados aos três fatos históricos ligados aos diferentes contextos sócio-políticos, o texto se enfocou nas quatro condições de produção do pensamento social (o formalismo espontâneo, o dualismo causal, a primazia da conclusão e a construção de analogia), entendendo-as como ativadoras de uma lógica de pensamento - diferente do científico-racional - que gera, circula e se reproduz nas redes sociais digitais.

Ao se tratar de um fenômeno que pode ser abordado a partir de uma multiplicidade de perspectivas teóricas e quadros metodológicos, da Deontologia Jornalística, passando pela Engenharia de Dados, até a Ciência Política e a Psicologia Social - o que enriquece sua compreensão e incentiva o debate e a pesquisa acadêmica -, vem à tona uma questão eminentemente epistemológica levantada por Von Hayek (1953), 16 anos antes que o projeto Arpanet começasse a operar como a gênese do que hoje é a Internet: "no que diz respeito às ações humanas, as coisas são o que as pessoas pensam que essas coisas são" (ROUQUETTE, 1994, p. 175, tradução nossa). Como analisado ao longo do texto, as redes sociais digitais, ao propiciarem a construção colaborativa e reprodução em tempo real de narrativas por vezes enviesadas ou manipuladas/manipuláveis do ponto de vista comunicacional, tornam-se o dispositivo par excellence de formação do pensamento social nas sociedades interconectadas da contemporaneidade, com efeitos diretos no Lebenswelt ou mundo da vida dos grupos humanos.

\section{Referências}

ABRIC, J. C. L'organisation interne des représentations sociales : système central et système périphérique. In: GUIMELLI, Christian (Org.). Structures et transformations des représentations sociales. Neuchâtel, Suisse: Delachaux et Niestlé, 1994.

\section{POLÊM!CA $\mid$ LABORE}

Polêmica - Revista Eletrônica da Uerj - Rua São Francisco Xavier, 524, $1^{\circ}$ andar bloco D, sl.1001 • Tels.: +55 21 2334-4088 / 4087 • http://www.e-publicacoes.uerj.br/index.php/polemica/index http://www.labore.uerj.br • laboreuerj@yahoo.com.br 
ALTO COMISIONADO PARA LA PAZ. Acuerdo general para la terminación del conflicto y la construcción de una paz estable y duradera. Bogotá, 2016. Disponível em: http://www.altocomisionadoparalapaz.gov.co/procesos-y-conversaciones/Documentos\%20compartidos/24-112016NuevoAcuerdoFinal.pdf. Acesso em: 23 fev. 2019.

ÁLVARO, J.L.; GARRIDO, A. Psicologia Social: perspectivas psicológicas e sociológicas. Tradução de Miguel Cabrera Fernandes. São Paulo: McGraw-Hill, 2006.

CASTELLS, M. Redes de indignação e esperança: movimentos sociais na era da internet. Rio de Janeiro: Zahar, 2013.

CENTRO NACIONAL DE MEMORIA HISTÓRICA (CNMH). ¡Basta ya! Memorias de guerra y dignidad: Informe general Grupo de Memoria Histórica. Bogotá: Imprenta Nacional de Colombia, 2013. Disponível em: http://www.centrodememoriahistorica.gov.co/descargas/informes2013/bastaYa/basta-ya-memorias-guerradignidad-new-9-agosto.pdf. Acesso em: 23 fev. 2019.

COLOMBIA. Elecciones Plebiscito 2016. Disponível em:

https://www.colombia.com/elecciones/2016/plebiscito/resultados/. Acesso em: 23 fev. 2019.

CONFERENCIA EPISCOPAL DE COLOMBIA. Comunicado sobre las orientaciones del Ministerio de Educación respecto a los manuales de convivencia de los colegios. 8 de agosto de 2016. Disponível em: https://www.cec.org.co/sites/default/files/Comunicado\%20Orientaciones\%20Ministerior\%20Educacio\%CC\%81 n.pdf. Acesso em: 23 fev. 2019.

CORTE CONSTITUCIONAL DE COLOMBIA. Sentencia T-478 de 2015 sobre discriminación por orientación sexual o identidad de género. 3 de agosto de 2015. Disponível em:

http://www.corteconstitucional.gov.co/inicio/T-478-15\%20ExpT4734501\%20(Sergio\%20Urrego).pdf. Acesso em: 23 fev. 2019.

DICTIONARY OF OXFORD. Word of the Year is... 2016. Disponível em: https://en.oxforddictionaries.com/word-of-the-year/word-of-the-year-2016. Acesso em: 23 fev. 2019.

ECHEVERRI, G.; WOLTER, R.P.; PEIXOTO, Á.R. Redes sociales digitales y pensamiento social: el caso de la ocupación de las escuelas de Río de Janeiro. Psicologia, Conocimiento y Sociedad, v. 9, n. 1, 2019.

GARCÍA, A. El género en los acuerdos. Blog La Perorata, 6 out. 2016. Disponível em: https://laperorata.wordpress.com/2016/10/06/el-genero-en-los-acuerdos/. Acesso em: 23 fev. 2019.

GUIMELLI, C. La pensée sociale. Paris: Presses Universitaires de France (PUF), 1999.

HAYEK, F. von. Scientisme et sciences sociales. Paris: Plon, 1953.

LAZZARATO, M. As revoluções do capitalismo: a política no império. Tradução de Leonora Corsini. Rio de Janeiro: Civilização Brasileira, 2006.

LEVY, D.; NEWMAN, N.; FLETCHER, R.; KALOGELOPOULOS, A.; NIELSEN, R.K. Digital News Report 2017. Instituto Reuters y Universidad de Oxford, 2017. Disponível em: http://www.digitalnewsreport.org/. Acesso em: 23 fev. 2019.

MALINI, F.; ANTOUN, H. @Internet e \#Rua: ciberativismo e mobilização nas redes sociais. Porto Alegre: Sulina, 2013.

MATHIESON, D. Una relación tormentosa: Reino Unido, Europa y 'Brexit'. Estudios de Política Exterior, n. 76 (versión digital), 2016. Disponível em: http://www.politicaexterior.com/articulos/economia-exterior/unarelacion-tormentosa-reino-unido-europa-y-brexit/. Acesso em: 23 fev. 2019.

\section{POLÊM!CA $\mid$ LABORE (M. (3)}

Polêmica - Revista Eletrônica da Uerj - Rua São Francisco Xavier, 524, $1^{\circ}$ andar bloco D, sl.1001 • Tels.: +55 21 2334-4088/4087 • http://www.e-publicacoes.uerj.br/index.php/polemica/index http://www.labore.uerj.br • laboreuerj@yahoo.com.br 
MAY, T. Prime Minister's Commons statement on triggering Article 50. Londres: GOV.UK, 2017. Disponível em: https://www.gov.uk/government/speeches/prime-ministers-commons-statement-on-triggeringarticle-50. Acesso em : 23 fev. 2019.

MOSCOVICI, S. La psychanalyse, son image et son public. Paris : PUF, 1961.

Des représentations collectives aux représentations sociales. In : JODELET, Denise (Org.). Les représentations sociales. Paris: PUF, 1989.

POLONSKI, V. Analysing the social media voices of the UK's EU referendum. Blog Medium, 15 maio 2016 a. Disponível em: https://medium.com/@slavacm/social-media-voices-in-the-uks-eu-referendum-brexit-orbremain-what-does-the-internet-say-about-ebbd7b27cf0f. Acesso em: 23 fev. 2019.

Impact of social media on the outcome of the EU referendum. Blog Views from Oxford, 2016b. Disponível em: http://www.ox.ac.uk/news-and-events/oxford-and-brexit/brexit-analysis/views-from-oxford. Acesso em: 23 fev. 2019.

PRICE, V. Opinión Pública. Guadalajara, México: Universidad de Guadalajara, 1992.

RAMÍREZ, J. El No ha sido la campaña más barata y efectiva de la historia. Periódico La República, Bogotá, 4 out. 2016. Disponível em: https://www.larepublica.co/asuntos-legales/actualidad/el-no-ha-sido-la-campana-masbarata-y-mas-efectiva-de-la-historia-2427891. Acesso em: 23 fev. 2019.

ROUQUETTE, M.-L. Sur la connaissance des masses: essai de psychologie politique. Préface de Serge Moscovici. Grenoble: Presses Universitaires de Grenoble, 1994.

La communication sociale. Paris: Dunod, 1998. Érès, 2009.

La pensée sociale: perspectives fondamentales et recherches appliquées. Toulouse, France: Éditions

Représentations et idéologie. In: DESCHAMP, J.-C.; BEAUVOIS, J.-L. (Org.). Des attitudes aux attributions. Grenoble, France: Presses Universitaires de Grenoble, 1996. p. 163-173.

SÁ, C. P. de. Estudos de Psicologia Social: história, comportamento, representações e memória. Rio de Janeiro: EdUERJ, 2015.

THE ECONOMIST. The art of lie. Editorial, 10 set. 2016. Disponível em: https://www.economist.com/news/leaders/21706525-politicians-have-always-lied-does-it-matter-if-they-leavetruth-behind-entirely-art. Acesso em: 23 fev. 2019.

THE ELECTORAL COMMISSION. EU referendum results. Disponível em: https://www.electoralcommission.org.uk/find-information-by-subject/elections-and-referendums/past-electionsand-referendums/eu-referendum/electorate-and-count-information. Acesso em: 23 fev. 2019

WOLTER, R. P.. Pensée sociale et situations de crise. Tese (Doutorado em Psicología Social) - Institut de Psychologie, Université Paris V René Descartes, París, 2008.

WOLTER, R.P.; GURRIERI, C.; SORRIBAS, E. Empirical illustration of the hierarchical organization of social thought: a domino effect? Interamerican Journal of Psychology, Porto Alegre, v. 43, n. 1, p. 1-11, 2009.

Recebido em: 24/02/2019.

Aceito em: 30/03/2019.

\section{POLÊM!CA $\mid$ LABORE}

Polêmica - Revista Eletrônica da Uerj - Rua São Francisco Xavier, 524, $1^{\circ}$ andar bloco D, sl.1001 • Tels.: +55 21 2334-4088 / 4087 • http://www.e-publicacoes.uerj.br/index.php/polemica/index http://www.labore.uerj.br • laboreuerj@yahoo.com.br 